\title{
A critical review of evidence concerning long-loop reflexes excited by muscle afferents in man
}

\author{
M. MICHAEL GASSEL ${ }^{1}$ \\ From the Department of Neurology, University of California School of Medicine, San Francisco, \\ California. 94122, U.S.A.
}

SUMMARY It is the thesis of this review that the origin of the intercurrent facilitation at 50 to $400 \mathrm{msec}$ in the standard recovery curve of the $\mathrm{H}$ reflex, evoked with paired stimuli, is a complex. It is composed importantly of central feedback effects from the conditioning reflex contraction, influences mediated by cutaneous group III afferent nerve fibres excited by the percutaneous stimulus, and with a possible additional modest contribution by long-loop, spino-bulbo-spinal influences.

Sherrington (1906) originally distinguished short spinal reflexes, with muscular responses within the same locality as that of the application of the stimulus, from long spinal reflexes evoked at a distance. The long spinal reflexes involved neck, trunk, and interlimb postural adjustments which appeared to irradiate from the local site of application of the stimulus and were of the type represented in the 'reflex figure'. They were less easily and regularly elicitable than short spinal reflexes. Lloyd (1942) early demonstrated changes in motor neurone excitability in the lower extremity with conditioning stimuli to the brachial plexus, and Gernandt and Megirian (1961) observed ascending effects upon brachial motor neurones from stimulation of the hindlimb in cats. These directly conducting ascending or descending long spinal pathways have been designated the 'propriospinal system'. The propriospinal system is a slowly conducting system with multiple crossings of the spinal cord (Gernandt and Megirian, 1961; Shimamura and Livingston, 1963).

More recently an additional longitudinally orientated system, differing from the classical long spinal reflex system, has been described. Gernandt and Shimamura (1961) noted that a subtetanic dose of strychnine sulphate was necessary to activate ascending interlimb responses in high spinal but not decerebrate cats, and the authors postulated an additional phasically active supraspinal loop which was interrupted in the high spinal preparation. Shimamura and colleagues (Shimamura, 1963; Shimamura and Livingston, 1963; Shimamura and Akert, 1965) further defined 'long-loop' reflexes with intricate organization. Afferent stimuli proceed centripetally ${ }^{1}$ This work was supported by NIH Grant NB-07562. to the bulbar reticular formation where they act to produce descending volleys which evoke serial ventral root discharge bilaterally. The long-loop system is rapidly conducting especially on the afferent side. It was demonstrated that the slowly conducting direct 'propriospinal' influences and more rapidly conducting long-loop, spino-bulbo-spinal effects arrive simultaneously in the forelimb on stimulation of hindlimb afferents providing synchronous impetus to motor neurone discharge. A similar coincidence occurs in the hindlimb on stimulating forelimb afferents. This coincidence is thought to provide a ? bulbar integrating effect on interlimb reflexes.

Long-loop reflexes occur predominantly with stimulation of cutaneous nerves or dorsal roots. Stimuli applied to a muscle nerve produce reflex discharges which are of low amplitude and inconstant (Shimamura and Livingston, 1963; Shimamura and Akert, 1965). Removal of the cerebellum has been variously reported to reduce (Gernandt and Shimamura, 1961) or to have no effect on (Shimamura and Livingston, 1963) the spino-bulbo-spinal reflexes. It was later demonstrated that groups II and III muscle afferent nerve fibres, but not group I, were effective in evoking long-loop reflexes (Shimamura and Akert, 1965; Devanandan, Eccles, Lewis, and Stenhouse, 1966), although Eccles (1966) proposed an additional longloop reflex transmitted by impulses in group Ia fibres ascending to the cerebellum and effecting centrifugal discharge through vestibulospinal or reticulospinal tracts. Eccles's proposition, which is based upon evidence abstracted from experiments with man, has been influential in later attributions of important excitability changes evoked by muscle stretch or stimulation of group Ia afferent fibres in clinical 
neurophysiology, as long-loop in origin. It is the thesis of this review that the occurrence of long-loop reflexes on stimulation of muscle afferent fibres in man cannot be regarded as established, and, indeed, the preponderance of evidence supports explanations alternative to this proposition.

Long-loop effects have been purported to be demonstrated in man by the occurrence of a late phase of facilitation in the recovery curve of the monosynaptic reflex (H-reflex) evoked from the triceps surae muscle by paired electrical shocks of equal strength applied to the posterior tibial nerve in the popliteal fossa. This intercurrent facilitation occurs from about 50 to $400 \mathrm{msec}$, and peaks at $200 \mathrm{msec}$. It appears to be superimposed on a long-lasting depression beginning a few msec after the conditioning volley and gradually fading at two to five seconds (Fig. 1). Indeed, it is this phase of facilitation which appears to be the most sensitive parameter in disease states. It is enhanced and occurs with shorter latency in spasticity (Magladery, 1955; Olsen and Diamantopoulos, 1967); it is increased in Parkinsonian rigidity and decreased somewhat after successful thalamotomy (Olsen and Diamantopoulos, 1967; Yap, 1967); it is increased or decreased after spinal transection (Languth, Teasdall, and Magladery, 1952; Diamantopoulos and Olsen, 1967). It is argued that there is no process at spinal cord level whereby a group Ia afferent volley could produce such a delayed facilitation (Yap, 1967). Yet there are possible explanations to be considered other than that of late effects of the conditioning muscle afferent volley. The period of facilitation has otherwise been attributed to the central feed-back effects from

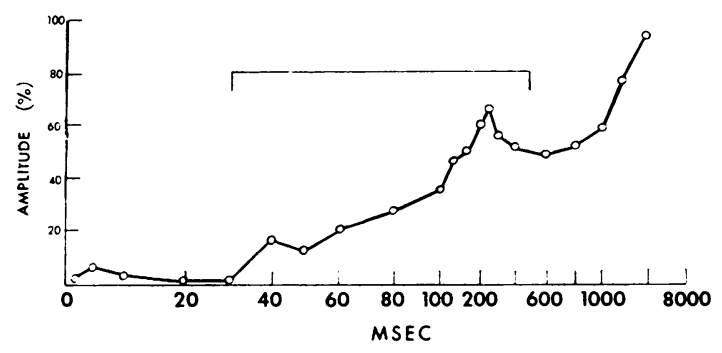

FIG. 1. Mean of recovery curves of the maximal $H$ reflex evoked in 15 normal subjects by paired electrical shocks of equal intensity applied to the posterior tibial nerve in the popliteal fossa. The late (intercurrent) facilitation is indicated by a superimposed bracket. Abscissa: interval between conditioning and test volleys. Ordinate: amplitude of test $H$ reflexes expressed as percentage of the conditioning reflexes. This figure is modified from a study of motor neurone excitability in man by Diamantopoulos and Olsen (1967). the conditioning reflex contraction (Paillard, 1955; Diamantopoulos and Olsen, 1967). After the conditioning reflex contraction, the muscle lengthens, stretching the spindle organ and exciting group Ia discharges, which in turn increase motor neurone excitability. A similar thesis is employed in explanation of muscle clonus. Indeed, experimental evidence has been advanced to relate this phase of facilitation with discharge of spindle afferent fibres at the onset of relaxation after a reflex contraction. Bianconi, Granit, and Reis (1964) found that this phase of facilitation of the monosynaptic reflex, recorded from the proximal stump of a divided central root, disappeared after the administration of Flaxedil, indicating the importance of muscle contraction in its evocation.

In support of the long-loop origin of the intercurrent facilitation, Eccles (1966) advanced the argument that the facilitation was absent in the recovery curves of spinal preparations, in which the spinobulbo-spinal reflexes would be expected to be interrupted. However, the importance of the temporal progression of the recovery curves after spinal shock in man provides perhaps the best evidence for the local spinal rather than the long-loop hypothesis for the origin of this phase of facilitation. Diamantopoulos and Olsen (1967) found that the facilitation was absent one to four days after the onset of spinal shock, about normal in size after one to four weeks, and considerably enhanced at two to three months after spinal transection. During the acute phase of spinal shock, with muscular flaccidity, the monosynaptic reflex evoked by sudden stretch of the triceps surae muscle (ankle jerk) is absent or greatly diminished, whereas that evoked from the same population of motor neurones by electrical stimulation of the posterior tibial nerve in the popliteal fossa proximal to the muscle mass ( $\mathrm{H}$ reflex) is either normal or only slightly reduced (Weaver, Landau, and Higgins, 1963; Diamantopoulos and Olsen, 1967). The electrically evoked reflex, which bypasses the muscle spindle mechanism, gives a measure of central excitability; whereas the relationship of the mechanically and electrically evoked monosynaptic reflexes provides some evidence for fusimotor function. Fusimotor paralysis and muscle spindle flaccidity are suggested by a particular depression of the ankle jerk (Gassel and Diamantopoulos, 1964). The absence of intercurrent facilitation in acute spinal shock at the time of spindle organ flaccidity and the enhancement of the facilitation in chronic spinal man, provide further support for the concept that this phase of facilitation originates from central feedback effects of spindle organ activation.

The spino-bulbo-spinal reflex origin of intercurrent facilitation has been supported by the results 
of the recovery curve of the electrically evoked monosynaptic reflex ( $\mathrm{H}$ reflex), using as conditioning stimulus an afferent volley sub-threshold or just threshold for evocation of an $\mathrm{H}$ reflex. Paillard (1955) first reported a slight intercurrent facilitation with such a sub-threshold stimulus. Clearly, the occurrence of a phase of facilitation with conditioning stimuli, which are sub-threshold for a reflex, would eliminate the contingency of backfiring from the stretched muscle spindle as a possible cause, and would appear to provide strong support for a longloop effect transmitted by group Ia fibres. Yet, the effects of stimulating cutaneous afferent fibres by the percutaneous stimulus need to be considered. Singleshock stimulation of the skin of the dorsal and plantar surfaces of the ipsilateral foot (Gassel and Ott, 1969) or of the anterolateral, anteromedial, and posterior surfaces of the leg (Gassel, 1970a) evokes a similar phase of facilitation with peak at 100 to 250 msec (Fig. 2). This effect has been attributed to influences transmitted by group III cutaneous fibres (Gassel and Ott, 1959). The attribution of the facilitation with conditioning stimuli sub-threshold for the $\mathbf{H}$ reflex to long-loop effects transmitted by group Ia fibres is therefore not established. The facilitation could well represent the effect of stimulation of group III cutaneous afferent fibres by the percutaneous stimulus.

Additional evidence bearing on the long-loop hypothesis has been advanced by experiments conditioning the $\mathrm{H}$ reflex with stretch of the ipsilateral triceps surae muscle. Paillard (1955) found that the recovery curve of the $\mathrm{H}$ reflex conditioned by the ankle jerk showed a more prominent inhibition and a lesser intercurrent facilitation than the recovery curve of paired $\mathrm{H}$ reflexes. On the other hand, when conditioning the ankle jerk with an $\mathrm{H}$ reflex or another ankle jerk, there was a long inhibition lasting to about $250 \mathrm{msec}$ with a relatively sudden return of the reflex to control levels. A slight excrescence of facilitation in the recovery curve was noted at $\mathbf{3 5 0}$ msec, particularly when conditioning the ankle jerk with the $\mathbf{H}$ reflex. Paillard also noted that passive dorsiflexion or plantar flexion of the ankle generally depressed the $\mathbf{H}$ reflex, although there was occasionally an increase with plantar flexion. Whereas dorsiflexion is generally recognized to cause pronounced depression of the $\mathrm{H}$ reflex (Magladery, 1955; Paillard, 1955), Yap (1967) has otherwise found it to accentuate the intercurrent facilitation and to accelerate the late recovery in both normal subjects and patients with spasticity. A system for sudden passive stretch of the ankle has been evolved (Taborikova, Provini, and Decandia, 1966a, b). Conditioning the $\mathrm{H}$ reflex with such sudden stretch evoked a phase of facilitation at about 100 to $500 \mathrm{msec}$, which is preceded and

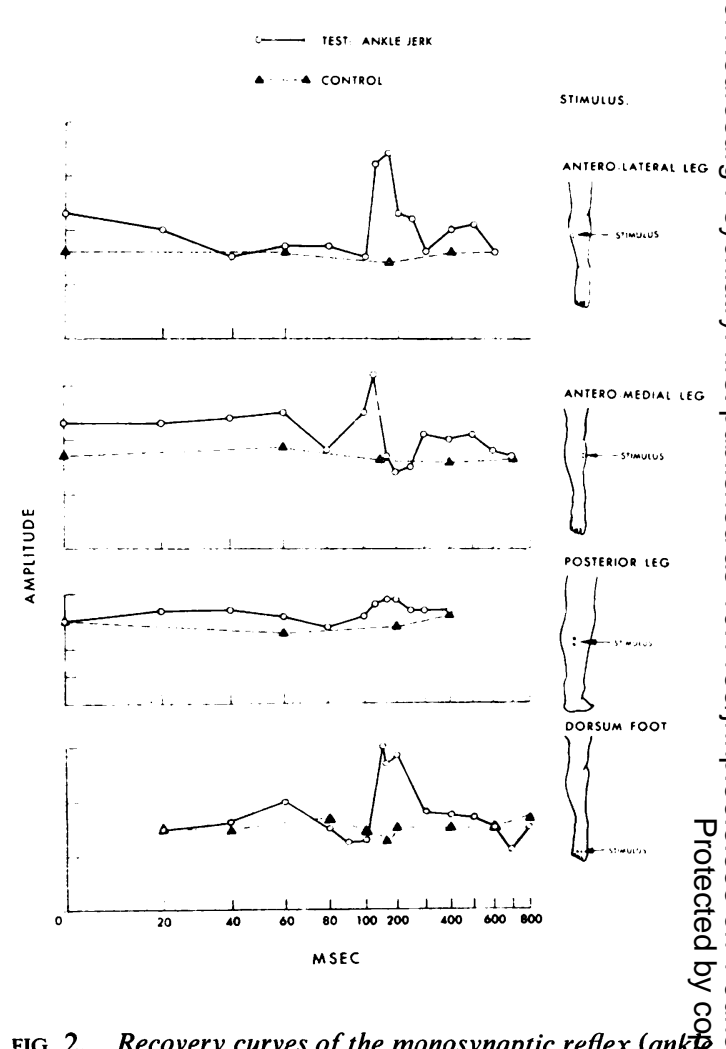

FIG. 2. Recovery curves of the monosynaptic reflex (ankte jerk) conditioned by a single shock stimulus delivered wi $\overrightarrow{0}$ subcutaneous electrodes to the ipsilateral mid leg, anterg lateral, anteromedial, and posterior surfaces in a normal subject, R.B. The conditioning stimulus was applied to the dorsum of the distal foot in subject P.K., in the bottom curve. Each graphic point represents the averaged amplitude $\bar{\partial}$ of eight reflexes. Control amplitudes were repeated during the investigation and are indicated in the graphs at the appropriate intervals. The figures are modified from the studies of the effects on motor neurone excitability of cutaneous stimulation in man (Gassel, 1970a).

followed by inhibition in most normal subjects tested. There are undoubtedly considerable difficulties with maintenance of constancy of the testing percutaneous stimulus vis-à-vis the posterior tibial nerve during $\delta$ such violent stretch; nevertheless, the conditions were sufficiently well controlled to lead Eccles (1966) 웅 to argue that there was no known manner in which the facilitation evoked by sudden passive stretch of the ankle could be caused by action restricted to the spinal cord. Thus, plantar flexion with stretch of $O$ anterior tibial muscles excites group Ia fibres with $N$ direct inhibition, via one interneurone, of antagonist posterior tibial muscles; group II and joint afferent 
fibres are inhibitory; whereas, Ia and Ib fibres together produce presynaptic inhibition of group Ia synaptic actions in the spinal cord. It is noteworthy that either sudden plantar flexion or dorsiflexion of the ankle were reported to evoke an intercurrent facilitation. This would necessitate the postulate of reflection of long-loop reflexes mediated by both flexor and extensor muscle afferent fibres to extensor motor neurones. Yet, analysis of the distribution has so far revealed long-loop reflexes from afferent fibres of extensor muscles to other extensors only (Shimamura and Akert, 1965). The protocol of the experiment conditioning the $\mathrm{H}$ reflex with passive movements at the ankle is complicated and difficult of control, and the evidence deserves only modest emphasis as an argument for long-loop influences.

A characteristic of long-loop reflexes, as originally defined, is the bilateral and widespread occurrence of the motor response. Long-loop reflexes were later reported to reflect to flexor muscles only, with stimulation of cutaneous afferent fibres; whereas, long-loop responses elicited from extensor muscle afferents were found to reflect to other extensor muscles (Shimamura and Akert, 1965). A study was made of excitability changes of the triceps surae motor neurones evoked by distant tendon jerks, which avoided the complication of autogenic central feed-back effects from the conditioning reflex contraction (Gassel, 1970a). Conditioning the $\mathrm{H}$ reflex or the ankle jerk with either the contralateral or ipsilatera! biceps jerk facilitated the monosynaptic reflex from 20 to $200 \mathrm{msec}$. A slight increment of facilitation occurred, peaking at about $200 \mathrm{msec}$ in two of seven subjects (Fig. 3). Some variation occurred in the pattern of effect on conditioning with the contralateral ankle jerk. There was facilitation starting at about $40 \mathrm{msec}$ and extending to $100 \mathrm{msec}$ followed by a mild depression lasting up to five seconds in nine of 15 subjects. Mild depression preceded the facilitation in three of 15 subjects. An additional mild and relative phase of facilitation occurred at 150 to $200 \mathrm{msec}$ in five of 15 studies (Fig. 3). It was concluded that there was evidence of long descending influence evoked in a population of triceps surae motor neurones by distant tendon jerk. The mild and relative late facilitation with peak at 150 to $200 \mathrm{msec}$, which occurred in seven of 22 investigations, as well as the late inhibition sometimes lasting up to five seconds, was interpreted as evidence suggestive of long-loop, spino-bulbo-spinal influences; although a direct long spinal reflex mediated by small afferent fibres could not be conclusively ruled out.

Shimamura, Mori, Matsushima, and Fujimori (1964) reported a 'long-loop response' in man occurring at a latency of 65 to $80 \mathrm{msec}$ in the tibialis
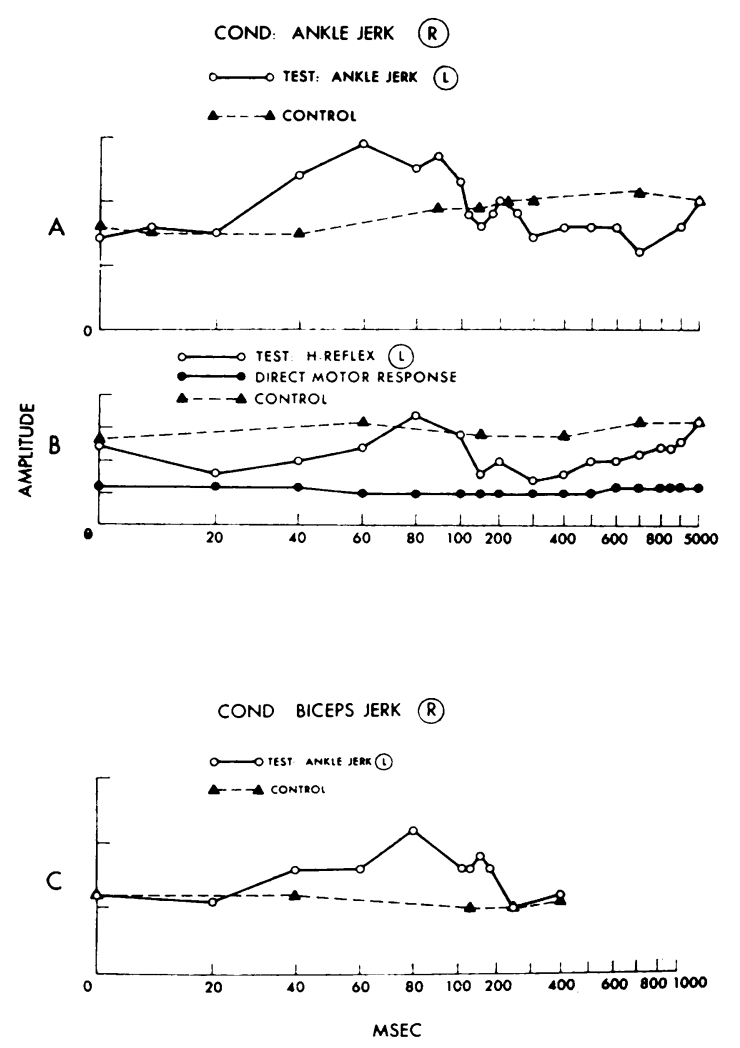

FIG. 3. A and $\mathrm{B}$ : the recovery curve of the monosynaptic reflex (ankle jerk in $A$ and $H$ reflex in $\mathrm{B}$ ) conditioned by the contralateral ankle jerk in normal subjects. $\mathrm{C}$ : the recovery curve of the ankle jerk conditioned by the contralateral biceps jerk. Each graphic point represents the averaged amplitude of eight reflexes. This figure is modified from a study of motor neurone excitability changes at a distance after tendon jerks (Gassel, in preparation).

anterior muscle on evocation of the $\mathrm{H}$ reflex with percutaneous stimulation of the posterior tibial nerve in the popliteal fossa. Delayed responses were not found on stimulation of the peroneal, femoral, or radial nerves. Kugelberg, Eklund, and Grimby (1960) and Ashworth, Grimby, and Kugelberg (1967) reported flexion reflex discharges in the tibialis anterior muscle in man at the same latency on stimulation of the plantar surface of the foot; a similar discharge evoked in chronic animal preparations was alse of appropriate latency for a flexion reflex (Gassel, Marchiafava, and Pompeiano, 1964). 


\section{REFERENCES}

Ashworth, B., Grimby, L., and Kugelberg, E. (1967). Comparison of voluntary and reflex activation of motor units; functional organization of motor neurones. J. Neurol. Neurosurg. Psychiat., 30, 91-98

Bianconi, R., Granit, R., and Reis, D. J. (1964). The effects of extensor muscle spindles and tendon organs on homonymous motor neurones in relation to $\gamma$-bias and curarization. Acta physiol. scand., 61, 331-347.

Devanandan, M. S., Eccles, R. M., Lewis, D. M., and Stenhouse, D. (Personal communication) (1966). Cited in: Eccles, J. C. (1966). Atti Accad. med. lombarda, 21, 158-176.

Diamantopoulos, E., and Olsen, P. Z. (1967). Excitability of motor neurones in spinal shock in man. J. Neurol. Neurosurg. Psychiat., 30, 427-431.

Gassel, M. M. (1970a). The role of skin areas adjacent to extensor muscles in motor neurone excitability: evidence bearing on the physiology of Babinski's response. $J$. Neurol. Neurosurg. Psychiat., 33, 121-126.

Gassel, M. M. (1970b). Motor neurone excitability changes at a distance after tendon jerks in humans (in preparation).

Gassel, M. M., and Diamantopoulos, E. (1964). The effect of procaine nerve block on neuromuscular reflex regulation in man. An appraisal of the role of the fusimotor system. Brain, 87, 729-742.

Gassel, M. M.. Marchiafava. P. L., and Pompeiano, O. (1964). Tonic and phasic inhibition of spinal reflexes during deep, desynchronized sleep in unrestrained cats. Arch. ital. Biol., 102, 471-499.

Gassel, M. M., and Ott, K. H. (1969). Local sign and late effects on motor neurone excitability of cutaneous stimulation in man. Brain (in press).

Gernandt, B. E., and Megirian, D. (1961). Ascending propriospinal mechanisms. J. Neurophysiol., 24, 364-376.

Gernandt, B. E., and Shimamura, M. (1961). Mechanisms of interlimb reflexes in cat. J. Neurophysiol., 24, 665-676.

Kugelberg, E., Eklund, K., and Grimby, L. (1960). An electromyographic study of the nociceptive reflexes of the lower limb. Mechanism of the plantar responses. Brain, 83, 394-410.
Languth, H. W., Teasdall, R. D., and Magladery, J. w으 (1952). Electrophysiological studies of the reflex activity in patients with lesions of the nervous system. III Motor neurone excitability following afferent nerve volleys in patients with rostrally adjacent spinal corde damage. Bull. Johns Hopk. Hosp., 91, 257-266.

Lloyd, D. P. C. (1942). Mediation of descending long spinato reflex activity. $J$. Neurophysiol., 5, 435-458.

Magladery, J. W. (1955). Some observations on spinal re flexes in man. Pfüger's Arch. ges. Physiol., 261, 302-321

Olsen, P. Z., and Diamantopoulos, E. (1967). Excitability of spinal motor neurones in normal subjects and patients with spasticity, Parkinsonian rigidity, and cerebellar hypotonia. J. Neurol. Neurosurg. Psychiat., 30, 325-331

Paillard, J. (1955). Réflexes et Régulations d'Origine Proprioceptive chez l'Homme. Etude Neurophysiologique eto Psychophysiologique. Librairie Arnette: Paris.

Sherrington, C. S. (1906). The Integrative Action of the Nervous System. Yale University Press: New Haven.

Shimamura, M. (1963). Longitudinal coordination betweeno spinal and cranial reflex systems. Exp. Neurol., 8, 505-s 521.

Shimamura, M., and Akert, K. (1965). Peripheral nervousrelations of propriospinal and spino-bulbo-spinal refiex $\vec{\omega}$ systems. Jap. J. Physiol., 15, 638-647.

Shimamura, M., and Livingston, R. B. (1963). Longitudina conduction systems serving spinal and brain-stem coz ordination. J. Neurophysiol., 26, 258-272.

Shimamura, M., Mori, S., Matsushima, S., and Fujimori, $B$ (1964). On the spino-bulbo-spinal reflex in dogs $\omega$ monkeys and man. Jap. J. Physiol., 14, 411-421.

Taborikova, H., Provini, L., and Decandia, M. (1966) Evidence that muscle stretch evokes long-loop refleses from higher centres. Brain Res., 2, 192-194.

Taborikova, H., Provini, L., and Decandia, M. (1966). (Unpublished observations.) Cited in: Eccles, J. ¿્ડ (1966), Atti Accad. med. lombarda, 21, 158-176.

Weaver, R. A., Landau, W. M., and Higgins, J. F. (196) Fusimotor function. Part II. Evidence of fusimotor depression in human spinal shock. Arch. Neurol. (Chic.) 9, 127-132

Yap, C.-B. (1967). Spinal segmental and long-loop reflexes on spinal motoneurone excitability in spasticity and rigidity. Brain, 90, 887-896. 